\title{
Only few benefits from propylene glycol drench in early lactation for cows identified as physiologically imbalanced based on milk spectra analyses
}

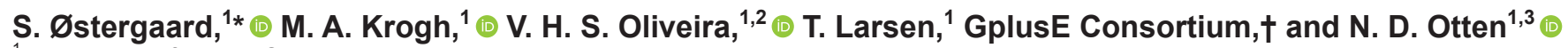 \\ ${ }^{1}$ Department of Animal Science, Aarhus University, Blichers Allé 20, DK-8830 Tjele, Denmark \\ ${ }^{2}$ Department of Disease Control and Epidemiology, National Veterinary Institute, SE-751 89, Uppsala, Sweden \\ ${ }^{3}$ Department of Veterinary and Animal Sciences, University of Copenhagen, Grønnegårdsvej 8, 1870 Frederiksberg C, Denmark
}

\begin{abstract}
The main objective of this study was to test the efficiency of a management system combining metabolic clustering of cows based on Fourier-transform midinfrared (FT-MIR) spectra of milk and targeted treatment of metabolically imbalanced cows with propylene glycol drench. We hypothesized that cows identified in a metabolically imbalanced status during early lactation were associated with subsequent impaired health, reproduction, and production, and that treatment with propylene glycol treatment would improve health, reproduction, and production relatively more in these cows than in control cows. We completed a prospective, randomized controlled trial with 356 earlylactation cows in 2 private dairy herds in Denmark from December 2017 to April 2018. Milk samples of cows were collected before treatment, from 4 to $9 \mathrm{~d}$ in milk, and after treatment, from 22 to $27 \mathrm{~d}$ in milk. Milk
\end{abstract}

Received July 3, 2019.

Accepted October 21, 2019.

*Corresponding author: soren.ostergaard@anis.au.dk

$\dagger$ List of authors in GplusE Consortium: Mark Crowe, Niamh McLoughlin, Alan Fahey, Fiona Carter, Elizabeth Matthews, Andreia Santoro, Colin Byrne, Pauline Rudd, Roisin O'Flaherty, Sinead Hallinan, Claire Wathes, Mazdak Salavati, Zhangrui Cheng, Ali Fouladi, Geoff Pollott, Dirk Werling, Beatriz Sanz Bernardo, Conrad Ferris, Alistair Wylie, Matt Bell, Mieke Vaneetvelde, Kristof Hermans, Miel Hostens, Geert Opsomer, Sander Moerman, Jenne De Koster, Hannes Bogaert, Jan Vandepitte, Leila Vandevelde, Bonny Vanranst, Klaus Ingvartsen, Martin Tang Sorensen, Johanna Hoglund, Susanne Dahl, Soren Ostergaard, Janne Rothmann, Mogens Krogh, Else Meyer, Leslie Foldager, Charlotte Gaillard, Jehan Ettema, Tine Rousing, Torben Larsen, Victor H. Silva de Oliveira, Cinzia Marchitelli, Federica Signorelli, Francesco Napolitano, Bianca Moioli, Alessandra Crisà, Luca Buttazzoni, Jennifer McClure, Daragh Matthews, Francis Kearney, Andrew Cromie, Matt McClure, Shujun Zhang, Xing Chen, Huanchun Chen, Junlong Zhao, Liguo Yang, Guohua Hua, Chen Tan, Guiqiang Wang, Michel Bonneau, Marlène Sciarretta, Armin Pearn, Arnold Evertson, Linda Kosten, Anders Fogh, Thomas Andersen, Matthew Lucy, Chris Elsik, Gavin Conant, Jerry Taylor, Deborah Triant, Nicolas Gengler, Michel Georges, Frederic Colinet, Marilou Ramos Pamplona, Hedi Hammami, Catherine Bastin, Haruko Takeda, Aurelie Laine, Anne-Sophie Van Laere, Rodrigo Mota, Saied Naderi Darbagshahi, Frederic Dehareng, Clement Grelet, Amelie Vanlierde, Eric Froidmont, Frank Becker, Martin Schulze, and Sergio Palma Vera. samples were analyzed using FT-MIR spectroscopy. We also measured 4 milk metabolites ( $\beta$-hydroxybutyrate, isocitrate, malate, and glutamate) and fat and protein contents. Based on FT-MIR spectra and cluster analyses, cows were clustered into groups of metabolically imbalanced and healthy cows. Within each group, cows were allocated randomly to treatment with propylene glycol $(500 \mathrm{~mL}$ for $5 \mathrm{~d}$ ) or no treatment. We analyzed the effect of the treatment on cow-level variables: metabolic cluster, milk metabolites, fat and protein contents, and fat-to-protein ratio at a milk sampling after the treatment. Furthermore, we analyzed daily milk yield, calving to first service interval, and disease occurrence. Results showed only a few effects of propylene glycol treatment and few interactions between treatment and metabolic clusters. We found no significant main effects of propylene glycol treatment in any of these analyses. A negative effect of the imbalanced metabolic cluster was found for the outcome of calving to first service interval for multiparous cows. In conclusion, we found a longer calving to first service interval in metabolically imbalanced cows, but we were not able to demonstrate overall benefits from the applied detection of cows in imbalanced metabolic status in early lactation and follow-up by treatment with propylene glycol.

Key words: physiological and metabolic imbalance, milk biomarker, propylene glycol, dairy cow

\section{INTRODUCTION}

Cows in early lactation are challenged by the rapid increase in milk yield, risk of detrimental negative energy balance, imbalanced metabolic status or physiological imbalance, and subsequent compromised health, production, and reproduction status (Overton et al., 2017). Physiological imbalance is an increased risk of subclinical and clinical manifestations of other health disorders due to a metabolic challenge (Moyes et al., 2013). Because physiological imbalance has no clinical signs, efforts have been directed toward detection by biomarkers. Most biomarkers of physiological imbalance 
are based on measurements of blood metabolites [e.g., BHB, nonesterified fatty acids (NEFA), glucose, and urea] and hormones, particularly serum IGF-1 (Chagas et al., 2007; Wathes et al., 2007; Ingvartsen and Moyes, 2013). Several reviews (Ingvartsen et al., 2003; Ingvartsen, 2006; LeBlanc, 2010) identified plasma NEFA, $\mathrm{BHB}$, and glucose as major metabolites that relate to degree of physiological imbalance. Further, these reviews suggested that biomarkers combining a greater number of metabolites would be better than individual blood metabolites and hormones for assessing periparturient cow metabolic status. Moyes et al. (2013) defined an index of physiological imbalance based on weekly measures of blood metabolites of NEFA, BHB, and glucose. This prepartum physiological imbalance index and plasma NEFA were better predictors of disease (i.e., metritis, retained placenta, and milk fever) at 1 wk postpartum than energy balance and plasma BHB and glucose (Moyes et al., 2013). Aiming to integrate such biomarkers in cow- and herd-management on a daily basis in a commercial herd setting has directed research on biomarkers of physiological imbalance to milk metabolites (Overton et al., 2017). Recently, the GplusE project has published results on clustering of cows in physiological imbalance based on measurements in milk based on data from 234 cows from research herds in 6 countries (De Koster et al., 2019; Grelet et al., 2019). Based on glucose, BHB, NEFA, and IGF-1 in blood, cows were clustered into 3 metabolic groups: balanced cows, cows in physiological imbalance, and "intermediate cows." When discriminating cows with imbalanced metabolic status from those with healthy and moderately affected metabolic status, milk FTMIR spectra were able to distinguish the imbalanced group with a global percentage of correct classification up to $92 \%$ (Grelet et al., 2019).

Until now, research on metabolic status using the above-mentioned techniques has considered milk samples from cows in research herds, where the incidence of health problems was low. Moreover, the metabolic clustering based on milk samples has not been challenged on its potential to efficiently reduce health problems when implemented in a system that combines both detection and intervention.

Propylene glycol (PRG) has been used to treat ketosis since 1950 (Nielsen and Ingvartsen, 2004; Lomander et al., 2012). McArt et al. (2011, 2012) showed that oral drenching with PRG helped to revert hyperketonemia and reduced risks of abomasum displacement, decreased early-lactation culling risk, and increased milk production. Accordingly, PRG drench is potentially an efficient intervention for physiological imbalance.

The objective of this study was to test the efficiency of a management system that combined metabolic clus- tering of cows based on milk FT-MIR spectral data and targeted intervention of metabolic imbalanced cows with treatment with PRG. We hypothesized that cows identified in a metabolically imbalanced status by means of milk FT-MIR during early lactation are prone to have subsequent impaired health, reproduction, and production compared with control cows and that the PRG treatment can, to some extent, overcome these impairments. To validate the applied metabolic clustering, we assessed 4 milk metabolites as alternative biomarkers.

\section{MATERIALS AND METHODS}

\section{Experimental Herds and Animals}

Two herds (A and B) were selected by convenience sampling due to their location of driving distance from the Foulum Campus of Aarhus University, Denmark. Furthermore, the herds had a large number of cows (761 in herd A and 1,130 in herd B) for herds in Denmark. The farmers agreed to collect milk samples from cows according to a protocol and to share production, reproduction, and disease treatment records from their herds. The herds were managed under a freestall housing system with cubicles and parallel milking parlors. The predominant breed of cows was Danish Holstein. The main roughage sources in the diets were corn and grass silage. During the study period, the herds did not use prophylactic treatment with PRG or other specific energy supplements of certain cows. If the veterinarian diagnosed a cow with primary ketosis that required treatment, the case was registered as a disease treatment. Production values for the 2 experimental dairy herds are given in Table 1.

Cows calving from the experiment starting date were considered eligible for inclusion. Herds were visited on the same weekday during the study for collection of milk samples. A total of 356 cows (herd A, $\mathrm{n}=172$; herd $\mathrm{B}, \mathrm{n}=184$ ) were enrolled in the study. The alloca-

Table 1. Production key figures for the 2 experimental dairy herds from herd reports for the 12-mo period ending February 28, 2019

\begin{tabular}{lrr}
\hline Item & Herd A & Herd B \\
\hline No. of cows (average over the year) & 761 & 1,130 \\
Culling rate, \% & 23 & 39 \\
Milk yield, kg of ECM/cow & 12,100 & 11,600 \\
SCC, 10 ${ }^{3}$ cells/mL (geometric mean) & 189 & 228 \\
CFI $^{1}$ 10th percentile, d & 56 & 44 \\
Insemination rate, \% & 50 & 57 \\
Conception rate, \% & 44 & 35 \\
Dead cows per cow per year, \% & 5.4 & 5.0 \\
\hline
\end{tabular}

${ }^{1}$ Calving to first service interval. 
tion of cows to experimental groups and distribution according to parity are in Table 2 .

\section{Experimental Design}

The time period of the study was between December 12, 2017, and April 21, 2018. The experiment was a prospective, randomized controlled trial performed in the 2 herds (herds $\mathrm{A}$ and $\mathrm{B}$ ) using the individual cow as the experimental unit and with both negative and positive controls. Cows had milk samples collected before the experimental treatment, between 4 and 9 DIM, and after experimental treatment, between 22 and 27 DIM. Cows allocated for treatment received $500 \mathrm{~mL}$ of PRG daily for 5 consecutive days by oral drenching. The farm staff was responsible for administering the PRG at a specific time of day. This treatment was started $5 \mathrm{~d}$ after the milk sampling of cows at 4 to 9 DIM. Although the farmers had been informed about cows selected for treatment, they were blinded to the biomarker information used to assign cows to the treatment or control group.

By using milk FT-MIR spectral data as biomarker, metabolic clusters were predicted directly, and thereby cows were grouped in the 2 metabolic clusters: (1) metabolically imbalanced status ("imbalanced"), and (2) healthy and moderately affected metabolic status ("healthy") as described by Grelet et al. (2019). We used 2 separate predictive models documented by Grelet et al. (2019), one for cows in first parity and another predictive model for cows in second parity or older. The model used partial least squares discriminant analysis for predicting imbalanced status. The predictor was milk FT-MIR and the response variable was the metabolic status of the cows as defined by k-means clustering based on 4 blood components analyzed by reference analysis (Grelet et al., 2019). Accuracy of these models in classifying cows correctly compared with the clustering of metabolic status determined through blood measurements was reported to be high (85 to $92 \%$ ) in the study of Grelet et al. (2019).
Thereby, we allocated cows randomly to 1 of 4 experimental groups: healthy cows without treatment control (HC), healthy cows with PRG treatment $(\mathbf{H T})$, imbalanced cows without treatment control (IC), and imbalanced cows with PRG treatment (IT). The allocation procedure was done separately for parities 1,2 , and $3+$ to ensure representative number of cows from different parities in each group.

The milk sampling in herd B from 4 to 9 DIM was replicated on 2 consecutive days to assess of day-today consistency of the FT-MIR-based classification of imbalanced and healthy within cows.

\section{Sampling and Analysis of Milk}

Milk was sampled during the whole study period between December 12, 2017, and April 21, 2018. After initial and follow-up supervision, farm staff collected these samples during morning milking. Electronic milk meters from DeLaval (herd A; DeLaval, Tumba, Sweden) and BouMatic (herd B; BouMatic LLC, Madison, WI) were used for volume-proportional sampling of milk. The samples were cooled immediately to $4^{\circ} \mathrm{C}$ until analysis. Within $18 \mathrm{~h}$ after collection (most common 6 to $8 \mathrm{~h}$ ), milk samples were homogenized and aliquots of $50 \mathrm{~mL}$ were analyzed at $40^{\circ} \mathrm{C}$ using a Milkoscan FT2 (Foss Analytical, Hillerød, Denmark) to retrieve the FT-MIR spectrum and fat and protein percentages. We used aliquots of $8 \mathrm{~mL}$ of milk to determine concentration of metabolites as biomarkers; namely, BHB (Larsen and Nielsen, 2005), isocitrate (isoC) (Larsen, 2014), malate (Mal), and glutamate (Glut) (Larsen and Fernández, 2017). These were analyzed in the Aarhus University laboratory (Denmark). These were chosen based on previous research in the field of milk biomarkers. Elevated levels of BHB in milk are obviously connected to recognized cases of ketosis (Larsen and Nielsen, 2005) and reduced energy intake (Pires et al., 2018). Chaiyabutr et al. (1981) demonstrated a significant decline in milk Mal and increase of milk isoC when goats were exposed to temporary starvation.

Table 2. The number of cows from each herd included in the study, allocation of cows to experimental groups, and distribution according to parity

\begin{tabular}{|c|c|c|c|c|c|c|c|c|}
\hline \multirow[b]{3}{*}{ Parity } & \multicolumn{8}{|c|}{ Experimental group ${ }^{1}$} \\
\hline & \multicolumn{4}{|c|}{ Herd A $(\mathrm{n}=172)$} & \multicolumn{4}{|c|}{ Herd B $(\mathrm{n}=184)$} \\
\hline & $\mathrm{HC}$ & HT & IC & IT & $\mathrm{HC}$ & $\mathrm{HT}$ & IC & IT \\
\hline 1 & 14 & 12 & 7 & 6 & 22 & 23 & 12 & 13 \\
\hline 2 & 14 & 12 & 14 & 14 & 10 & 13 & 11 & 10 \\
\hline $3+$ & 20 & 20 & 21 & 18 & 13 & 12 & 24 & 21 \\
\hline
\end{tabular}

${ }^{1} \mathrm{HC}=$ healthy cluster and control (no treatment); $\mathrm{HT}=$ healthy cluster and treatment with propylene glycol drench; IC = imbalanced cluster and control; IT = imbalanced cluster and treatment. 
Further, Pires et al. (2018) observed markedly reduced levels of Glut in milk and increased levels of isoC during feed restrictions in milking cows.

\section{Production, Reproduction, and Disease Treatment Data}

Cow-level milk yield per milking was measured using milk meters. Information on parity, calving date, and insemination dates, together with disease recordings, were obtained from the Danish Cattle Database.

For analyses of the effect of metabolic cluster and treatment with PRG drench on cow production, reproduction, and disease treatment, we defined 8 response variables. These included 4 response variables retrieved from the milk yield and milk analyses during 22 to 27 DIM: (1) fat \%, (2) protein \%, (3) fat-to-protein ratio, and (4) mean daily milk yield during 22 to 27 DIM. Four additional response variables were retrieved from specified periods: (5) calving to first service interval (CFI; d), (6) change in mean daily milk yield from before (4 to 9 DIM) to after PRG treatment (22 to 27 DIM), (7) diseases-1 (disease occurrence in the first 21 DIM; yes/no), and (8) diseases-2 (disease occurrence from 22 to 100 DIM; yes/no).

\section{Analytical Approach}

Descriptive statistics were used to provide information about response variables with calculation of median values and interquartile ranges over the experimental groups.

The data from herd $\mathrm{B}$ on the replicated milk samples on d 1 and 2 after the first milk sample from each cow from 4 to 9 DIM were analyzed by frequency of replicated measures being consistent or changed during 2 consecutive samplings in the same cow.

The data were analyzed with 4 statistical models to study the efficiency of detection of metabolic imbalanced cows by milk analysis combined with targeted treatment with PRG. Models 1 and 3 were for the classification of the metabolic clusters using milk FT-MIR analyses, and models 2 and 4 were to evaluate whether the continuous variables of the 4 metabolites had similar predictive power as the FT-MIR-based biomarker.

The treatment effects of PRG treatment on continuous outcome variables were analyzed by ANOVA models, and binomial outcome variables were analyzed by logistic regression models. Parity group was defined as a 3-level category (1, 2, and 3+), and all models were analyzed separately for each parity group. The explanatory variables for treatment and metabolic cluster or the 4 milk metabolites (BHB, isoC, Mal, or Glut) from milk samples at 4 to 9 DIM and the interaction between these were included in all models. The "herd" factor was included as a 2-level category fixed effect in all models. The model-building strategy was to include these forced variables and additional selected variables as described in detail for each model in the following. Model selection was performed using backward elimination of the additional variables using the stepwise function based on the Akaike information criterion. Continuous outcomes included fat \%, protein $\%$, fat-to-protein ratio, mean daily milk yield, change in mean daily milk yield from before (4 to 9 DIM) to after PRG treatment (22 to 27 DIM), and CFI. Dichotomous outcomes included the occurrence of diseases within 0 to 21 DIM (diseases 1) and 22 to 100 DIM (diseases 2).

All models were screened for curve linearity of the continuous explanatory variables, and all 2-way interactions terms were included in the model screening. All variables were assessed for homoscedasticity resulting in mean centering of the variables fat \%, protein \%, and fat-to-protein ratio and the $\log _{10}$ transformation of BHB and cube root transformation of Mal and Glut for further analyses.

Model 1 used to analyze the effect of PRG treatment and metabolic cluster 4 to 9 DIM on metabolic cluster 22 to 27 DIM was

$$
\begin{gathered}
\text { Cluster22to27 }=\text { PRG }+ \text { Cluster4to9 }+ \text { PRG } \\
\times \text { Cluster4to } 9+\text { Herd }
\end{gathered}
$$

where Cluster22to27 was metabolic cluster from milk sample 22 to 27 DIM (healthy, imbalanced); PRG was treatment group (no, yes); Cluster4to9 was metabolic cluster from milk sample 4 to 9 DIM (healthy, imbalanced); and Herd was study herd (A, B). Model 1 was analyzed by logistic regression and applied separately for the 3 parity groups.

Model 2 used to analyze the effect of PRG treatment and physiological status measured by metabolites from the milk sampling at 4 to 9 DIM on physiological status measured by metabolites from the milk sampling at 22 to 27 DIM was

$$
\begin{gathered}
\text { Metabolites22to27 }=\text { PRG }+ \text { Metabolites4to9 } \\
+ \text { PRG } \times \text { Metabolites4to } 9+\text { Herd }
\end{gathered}
$$

where Metabolites22to27 was the concentration of each metabolite (BHB, isoC, Mal, or Glut) from the milk sampling at 22 to 27 DIM; PRG was treatment group (no, yes); Metabolites4to9 was the concentration of each metabolite (BHB, isoC, Mal, or Glut) from the milk sampling at 4 to 9 DIM; and Herd was study herd 
(A, B). Model 2 was analyzed by ANOVA and applied separately for the 12 combinations of 3 parity groups and 4 milk metabolites.

Model 3 used to analyze the effect of PRG treatment and metabolic cluster 4 to 9 DIM on production, reproduction, and disease treatment outcome variables was

$$
\begin{aligned}
\mathrm{Y}_{\mathrm{i}}= & \text { PRG }+ \text { Cluster4to9 }+ \text { PRG } \\
& \times \text { Cluster4to9 }+ \text { Herd },
\end{aligned}
$$

where $\mathrm{Y}_{\mathrm{i}}(\mathrm{i}=1,2, \ldots, 8)$ was the 8 production, reproduction, and disease treatment outcome variables; PRG was treatment group (no, yes); Cluster4to9 was metabolic cluster from milk sample 4 to 9 DIM (healthy, imbalanced); and Herd was study herd (A, B). Model 3 was analyzed by ANOVA for the 6 continuous outcomes and by logistic regression for the 2 binomial outcomes variables of diseases. Model 3 was applied separately for the 24 combinations of 3 parity groups and 8 production, reproduction, and disease treatment outcome variables. In those 4 applications of model 3 in which the outcome variable was based on milk samples, the measurement from milk sampling at 4 to 9 DIM and associated 2-way interactions were initially included as explanatory variables.

Model 4 used to analyze the effect of PRG treatment and physiological status measured by metabolites from the milk sampling at 4 to 9 DIM on production, reproduction, and disease treatment outcome variables was

$$
\begin{aligned}
\mathrm{Y}_{\mathrm{i}}= & \mathrm{PRG}+\mathrm{BHB}+\text { isoC }+ \text { Mal }+ \text { Glut }+ \text { PRG } \\
\times \mathrm{BHB} & +\mathrm{PRG} \times \text { isoC }+\mathrm{PRG} \times \text { Mal } \\
& +\mathrm{PRG} \times \text { Glut }+ \text { Herd },
\end{aligned}
$$

where $\mathrm{Y}_{\mathrm{i}}(\mathrm{i}=1,2, \ldots, 8)$ was the 8 production, reproduction, and disease treatment outcome variables; PRG was treatment group (no, yes); BHB, isoC, Mal, and Glut were the concentrations of the metabolite from the milk sampling at 4 to 9 DIM; and Herd was study herd (A, B). Model 4 was analyzed by ANOVA for the 6 continuous outcomes and by logistic regression for the 2 binomial outcomes variables of diseases. Model 4 was applied separately for the 24 combinations of 3 parity groups and 8 production, reproduction, and disease treatment outcome variables. In those 4 applications of model 4 in which the outcome variable was based on milk samples, the measurement from the milk sampling at 4 to 9 DIM and associated 2-way interactions were initially included as explanatory variables.

Data were imported into a SQL Server database (Microsoft Corp., Redmond, WA) and all data handling and analyses were performed using $\mathrm{R}$ software version
3.4.4 (R Core Team, 2018). Results are presented using a significance level of $P<0.05$. Normality was assessed by means of Shapiro-Wilk test and model fit was further evaluated by checking the residuals against the fitted values and quantile-quantile (Q-Q) plots.

\section{RESULTS}

\section{Descriptive Results}

Results for milk fat $\%$, protein $\%$, and fat-to-protein ratio, together with yield data, were complete for all 356 cows enrolled in the study. The results for milk metabolites BHB, isoC, Mal, and Glut were missing for 18 cows in the period of 4 to 9 DIM, and for 10 cows in the period of 22 to 27 DIM. Experimental groups differed across yield- and fat-related outcomes, as seen in Table 3. Milk yield and BHB levels were higher in imbalanced cows compared with healthy cows throughout the study period, regardless of treatment. Fat \% and fat-to-protein ratio were only higher in the period of 4 to 9 DIM in the imbalanced cows. Values of Glut were higher in the period from 22 to 27 DIM for imbalanced cows. Cows starting their lactation within the metabolic imbalance cluster tended to have longer CFI than healthy cows, regardless of treatment.

Disease frequencies did not show any consistent pattern between experimental groups and were prone to low incidences of disease during both periods before (total cases $=69$; incidence $=0.19)$ and after PRG treatment $($ total cases $=20$; incidence $=0.06$; Table 4 ) .

\section{Effect of PRG Treatment and Metabolic Cluster 4 to 9 DIM on Metabolic Cluster 22 to 27 DIM}

The model 1 null hypothesis of no effect of PRG treatment and no interaction between treatment and metabolic cluster from milk sample at 4 to 9 DIM could not be rejected in any of the 3 parity groups. The corresponding $P$-values from model 1 were $>0.10$.

The model 2 null hypothesis of no effect of PRG treatment and no treatment by physiological status (the 4 milk metabolites) interaction could not be rejected in any of the 12 combinations of 3 parity groups and 4 milk metabolites.

\section{Effect of PRG Treatment and Metabolic Cluster 4 to 9 DIM on Production, Reproduction, and Disease Treatment}

The model 3 null hypothesis of no effect of PRG treatment and no interaction between treatment and metabolic cluster from milk sampling at 4 to 9 DIM was rejected in 6 of the 27 models (Table 5). There 


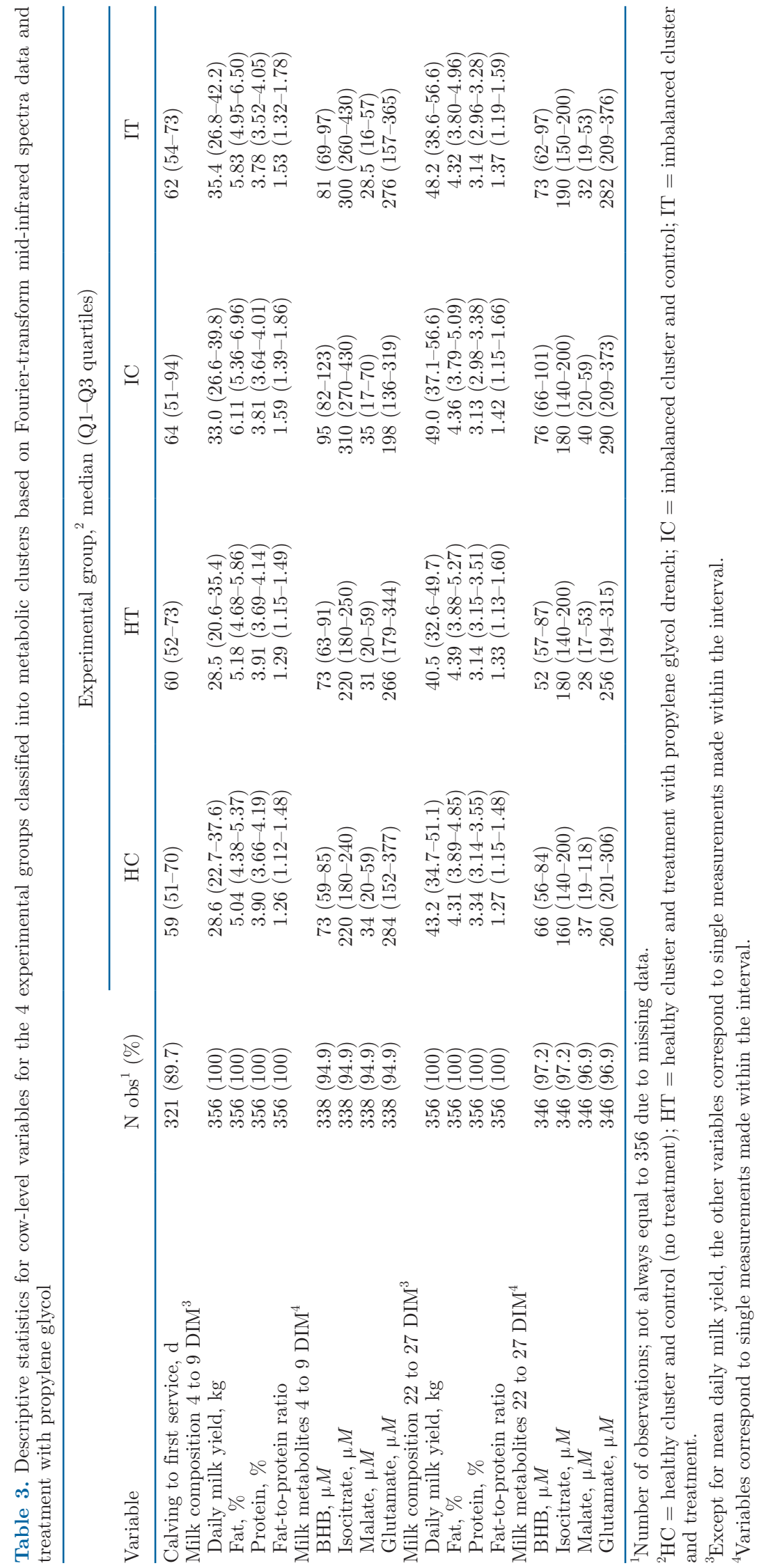


Table 4. Distribution of treated disease cases and categories from the period after calving to the end of propylene glycol treatment ( 0 to 21 DIM) compared with the period from the end of propylene glycol treatment to $100 \mathrm{~d}$ after calving (22 to 100 DIM) for each experimental group

\begin{tabular}{|c|c|c|c|c|c|c|c|c|}
\hline \multirow{2}{*}{ Disease } & \multicolumn{8}{|c|}{ Disease cases per experimental group ${ }^{1}$} \\
\hline & \multicolumn{4}{|c|}{0 to $21 \mathrm{DIM}$} & \multicolumn{4}{|c|}{22 to 100 DIM } \\
\hline Mastitis & 5 & 9 & 4 & 4 & 5 & 2 & 3 & 3 \\
\hline Ketosis & 1 & 2 & 1 & 0 & 0 & 0 & 1 & 0 \\
\hline Other metabolic disorders & 3 & 4 & 4 & 4 & 0 & 0 & 1 & 0 \\
\hline
\end{tabular}

${ }^{1} \mathrm{HC}=$ healthy cluster and control (no treatment); HT $=$ healthy cluster and treatment with propylene glycol drench; IC $=$ imbalanced cluster and control; IT = imbalanced cluster and treatment.

was no significant main effect of PRG treatment in any of the models. A negative effect of the imbalanced metabolic cluster was found for the outcome of CFI for parity $2(17.9 \pm 7.5 \mathrm{~d})$ and $3+$ cows $(18.9 \pm 5.9 \mathrm{~d}$; Table 6$)$. In parity $3+$ cows, we detected a tendency $(P$ $=0.07$ ) for an interaction between PRG treatment and metabolic cluster, showing a beneficial effect of PRG treatment $(-15.5 \pm 8.4 \mathrm{~d})$ in imbalanced cows relative to healthy cows.

The model 4 null hypothesis of no effect of PRG treatment and no interaction between treatment and physiological status measured by the milk metabolites (BHB, isoC, Mal, or Glut) from milk sampling at 4 to 9 DIM was rejected in 19 of the applied 27 models (Table 7). However, we detected no significant main effects of PRG treatment in any of the models. Additionally, none of the significant interactions between 1 of the 4 milk metabolites (BHB, isoC, Mal, or Glut) and PRG treatment was found simultaneously in more than one parity group. We found significant main effects of higher mean daily milk yield from 22 to 27 DIM and shorter CFI for parity $3+$ cows with lower concentrations of Mal and Glut. No such significant effects were found for parities 1 and 2 .

\section{Coefficient of Determination and Day-To-Day Consistency}

Explained variances for the forced models evaluating treatment outcomes did not differ largely between the 2 physiological status approaches (the metabolic cluster and the 4 milk metabolites). Generally, the coefficient of determination, $\mathrm{R}^{2}$, tended to be higher in models in which treatment or treatment-associated interactions showed significant effects for models including the 4 milk metabolites (BHB, isoC, Mal, or Glutam) rather than the metabolic cluster models; for example, protein $\%$ for parity 2 showed $\mathrm{R}^{2}=0.33$ for the metabolic cluster model and $\mathrm{R}^{2}=0.40$ for the model with the 4 milk metabolites.

Investigating the day-to-day consistency of metabolic clustering of cows generally showed lower consistency

Table 5. Effects of metabolic cluster from Fourier-transform mid-infrared spectra data in milk sample at 4 to 9 DIM, and treatment with propylene glycol, and their interaction effect on each of 8 production, reproduction, and disease treatment outcome variables (estimated by model 3$)^{1}$

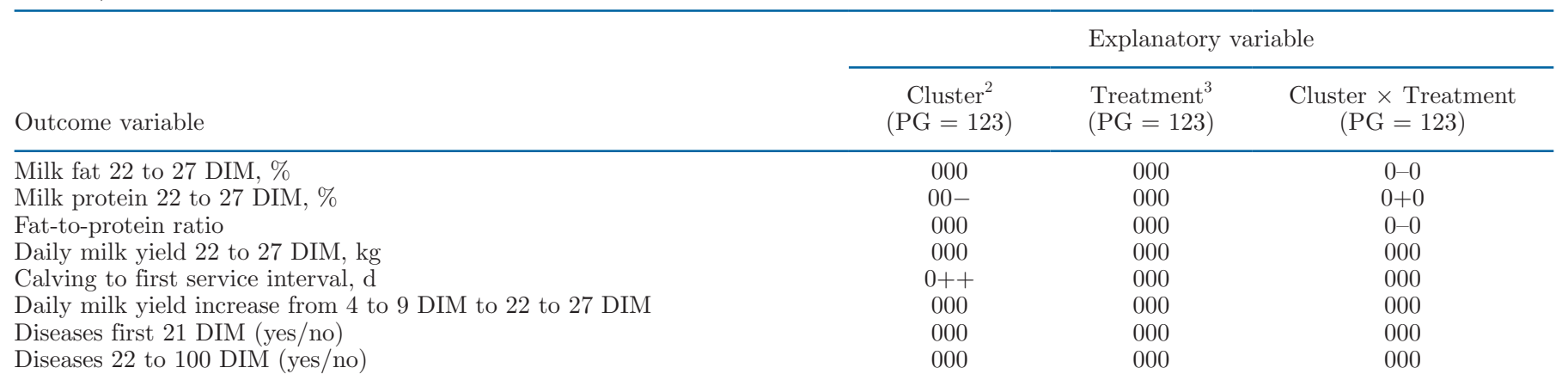

${ }^{1}$ Coding of effects: The 3 -digit sequences are for parity groups 1,2 , and 3 (parity $3+$ ) models; $0=$ no significant effect; $-=$ significant decreasing effect; $+=$ significant increasing effect, where baseline is healthy and no treatment. PG $=$ parity group.

${ }^{2}$ Metabolic cluster based on Fourier-transform mid-infrared spectra from milk sampling at 4 to 9 DIM (imbalanced versus healthy).

${ }^{3}$ Treatment with propylene glycol oral drenches for $5 \mathrm{~d}$ (treatment versus no treatment). 
Table 6. Parameter estimates of the effect of propylene glycol treatment and the interaction between treatment and metabolic cluster measured from 4 to 9 DIM on the outcome calving to first service interval (d) in an ANOVA model

\begin{tabular}{|c|c|c|c|c|c|c|c|}
\hline \multirow[b]{2}{*}{ Effect } & \multirow[b]{2}{*}{ Category $^{1}$} & \multicolumn{2}{|c|}{ Parity 1} & \multicolumn{2}{|c|}{ Parity 2} & \multicolumn{2}{|c|}{ Parity $3+$} \\
\hline & & $\begin{array}{l}\text { Estimate } \\
\quad(\mathrm{SE})\end{array}$ & $P$-value & $\begin{array}{l}\text { Estimate } \\
\quad(\mathrm{SE})\end{array}$ & $P$-value & $\begin{array}{l}\text { Estimate } \\
\quad(\mathrm{SE})\end{array}$ & $P$-value \\
\hline Intercept & & $76.9(5.2)$ & $<0.001$ & $68.6(6.0)$ & $<0.001$ & $70.6(4.8)$ & $<0.001$ \\
\hline Herd & Baseline & $-20.7(5.0)$ & $<0.001$ & $-12.6(5.3)$ & 0.02 & $-18.4(4.2)$ & $<0.001$ \\
\hline Treatment $(\mathrm{T})$ & PRG & $4.4(5.7)$ & 0.99 & $0.6(7.4)$ & 0.27 & $3.5(6.3)$ & 0.27 \\
\hline Cluster $^{2}(\mathrm{C})$ & Imbalanced & $7.9(7.0)$ & 0.82 & $17.9(7.5)$ & 0.02 & $18.9(5.9)$ & 0.04 \\
\hline
\end{tabular}

${ }^{1}$ Baseline $=$ herd $\mathrm{A}$, no treatment, and healthy cluster; PRG = propylene glycol drench.

${ }^{2}$ Metabolic cluster based on Fourier-transform mid-infrared spectra in milk sample at 4 to 9 DIM (healthy, imbalanced).

between $\mathrm{d} 1$ and 2 of milk sampling in herd B. For cows in parity $1,18 \%$ changed their metabolic cluster, whereas $11 \%$ of parity 2 cows and $25 \%$ of parity $3+$ cows changed their metabolic cluster. We found better consistency between the samples collected on d 2 and 3 , where $4 \%$ among parity 1, $6 \%$ among parity 2 , and $15 \%$ among parity $3+$ cows changed their metabolic cluster. Table 8 shows the results of day-to-day consistency.

\section{DISCUSSION}

In this study, we continued recent research conducted in research herds on FT-MIR monitoring of physiological imbalance in cows in early lactation (De Koster et al., 2019; Grelet et al., 2019). In the study of Grelet et al. (2019), a cluster with healthy cows had higher values for glucose and IGF-1; in addition, these cows had lower values for NEFA and BHB. In contrast, the cluster of cows in imbalanced status had lower values for glucose and IGF-1, higher values for NEFA, and lower or stagnant values for BHB.

Our objective was to test the efficiency of a management system combining metabolic clustering of cows based on milk FT-MIR spectra data and targeted intervention of physiological imbalanced cows with PRG oral drench treatment. The overall approach to study the implementation included (1) conducting the study in 2 large private herds with 356 early-lactating cows (1 mo after calving) as experimental units (study population); (2) using the milk sampling method used for routine milk recordings; (3) using an experimental randomized block design with treatment (yes, no) and cows grouped by parity $(1,2,3+)$ and metabolic cluster (imbalanced, healthy) using the methodology of Grelet et al. (2019); (4) administering a well-known and easy controllable cow treatment (PRG); and (5) using response variables from milk samples and production records. The modeling strategy was to analyze each parity separately and to analyze the data as 2-factorial (clustering, treatment) with interaction. With this approach, we were not able to demonstrate overall significant benefits of providing special treatment to cows identified as being in metabolic imbalance. We found no overall particular effect of PRG drench in imbalanced cows (i.e., no interaction). For most of the response variables, we found no effect of PRG treatment and no overall negative effect on the imbalanced cluster on production and disease treatment variables, whereas metabolic imbalance in multiparous cows had a detrimental effect on reproduction. The negative effect of the imbalanced metabolic cluster was found for the outcome of CFI for parity 2 $(17.9 \pm 7.5 \mathrm{~d})$ and $3+$ cows $(18.9 \pm 5.9 \mathrm{~d}$; Table 7$)$. In parity $3+$ cows, we detected a tendency $(P=0.07)$ for an interaction between PRG treatment and metabolic cluster, showing a beneficial effect of PRG treatment $(-15.5 \pm 8.4 \mathrm{~d})$ in imbalanced cows relative to healthy cows.

To compare the milk biomarker approach of using FT-MIR and clustering for metabolic imbalance to detect cows that need preventive treatment such as PRG, we also analyzed the same milk samples in a laboratory for 4 milk metabolites (BHB, isoC, Mal, or Glut) and replicated the statistical models with these 4 milk metabolites as an alternative to the FT-MIR cluster. In modeling the effect of PRG treatment and interaction between treatment and physiological status measured by the 4 milk metabolites from milk sampling at 4 to 9 DIM, we did not find significant main effects of PRG treatment in any of the models, and the few significant interactions between 1 of the 4 milk metabolites and PRG treatment were not found simultaneously in more than one parity group. In general, this approach with the 4 milk metabolites tended to explain more of the variation in the data, indicating that these 4 milk metabolites together had equal or greater predictive power than the FT-MIR clusters. However, the approach with 4 single milk metabolites was not able to predict cows with longer CFI as the approach based on FT-MIR clusters did. We have formerly seen minor but significant effects on milk BHB caused by lower digestibility 


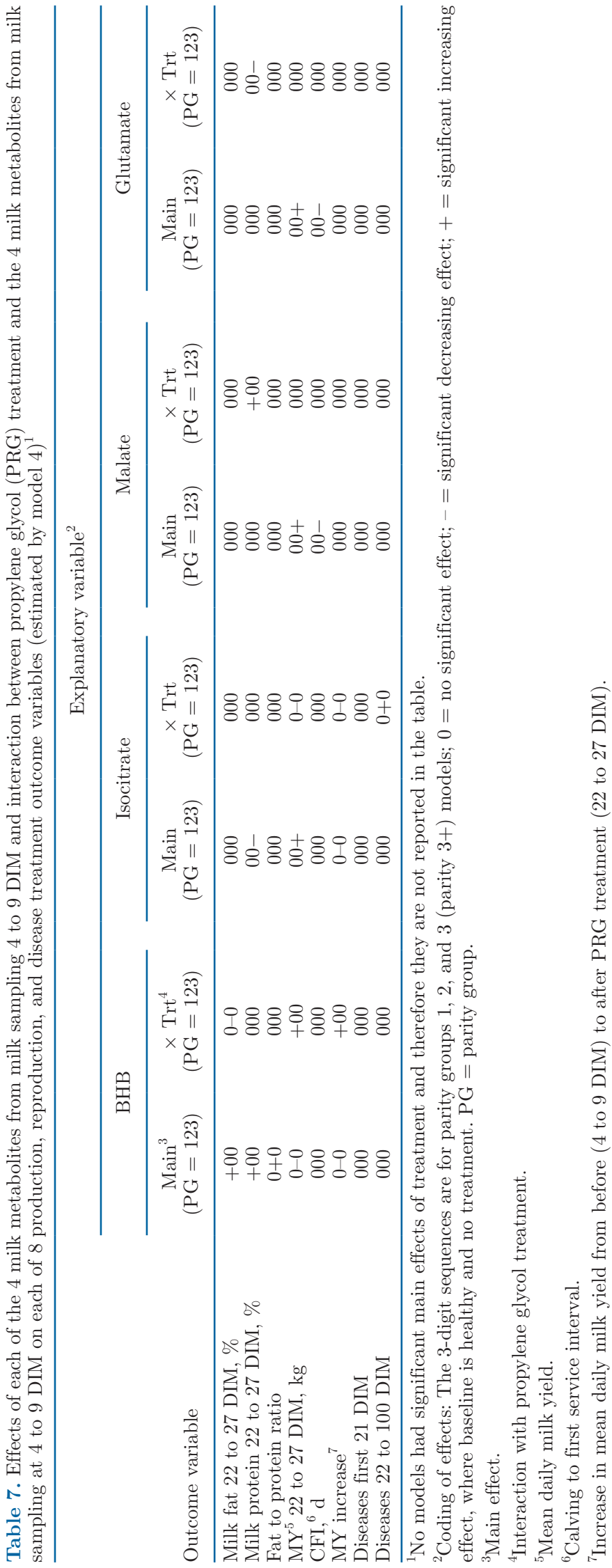

of feed or protein concentration (Larsen et al., 2016) and an effect on milk BHB and isoC during PRG treatment (Bjerre-Harpøth et al., 2016). In contrast to this, the present study showed reduced levels of milk isoC and BHB from the first sampling period (4 to 9 DIM) to the second (22 to 27 DIM) in all experimental groups irrespective of PRG treatment in between or not, indicating an effect of time rather than energy boost.

Using an alternative clustering of blood components, De Koster et al. (2019) developed predictive models for metabolic clusters using 3 sets of milk biomarkers (milk metabolites and enzymes, glycans on the immunogamma globulin fraction of milk, and FT-MIR spectra of milk). Their results supported the use of FTMIR-based biomarkers. Results showed that prediction of imbalanced cows, compared with balanced cows, was more accurate across all milk biomarkers where FT-MIR outperformed the other milk biomarkers (De Koster et al., 2019).

Propylene glycol is a glycogenic precursor that is either rapidly absorbed from the rumen and converted to glucose or partially metabolized to propionate in the rumen before being absorbed (Nielsen and Ingvartsen, 2004). A study conducted by McArt et al. (2011) with cows diagnosed with subclinical ketosis showed that the group treated with $300 \mathrm{~mL}$ of PRG as oral daily drenches were 1.50 times more likely to revert their subclinical ketosis than control cows; furthermore, the treated group were 0.54 times less likely to develop clinical ketosis than control cows. McArt et al. (2011, 2012) showed that oral drenching with PRG helped to revert hyperketonemia and reduce risks of abomasum displacement, decrease early-lactation culling risk, and increase milk production. Propylene glycol supplement for all early-lactating cows was also found to increase milk yield in the studies of Lomander et al. (2012; PRG supplement 0-21 DIM) and Shankare Gowda et al. (2015; PRG supplement 7 to 42 DIM). In the study of Lomander et al. (2012), the increased milk yield was not found in analyses of ECM, which might indicate that PRG induced a deprivation of milk protein or fat, as also previously reported (Nielsen and Ingvartsen, 2004; Liu et al., 2009). Other studies that investigated supplementation of cows with PRG; for example, Hoedemaker et al. (2004; 234 dairy cows from 13 d before parturition to 12 d after parturition), Liu et al. (2009; 33 cows; 1 to 63 DIM), and Borş et al. (2013; 200 cows; 0 to $7 \mathrm{DIM}$ ), found no general improvement in milk production. The 2 herds in our study were both well-managed herds at a high production level and with a low incidence of hyperketonemia (milk BHB $>100 \mu \mathrm{mol} / \mathrm{L}$ ). Hence, it is not surprising that we did not find overall increased milk production after PRG supplementation. 
Table 8. Consistency of metabolic clustering of cows based on Fourier-transform mid-infrared spectra data from milk samples collected on 3 consecutive days in herd B

\begin{tabular}{|c|c|c|c|c|c|}
\hline \multirow[b]{2}{*}{ Parity } & \multirow[b]{2}{*}{ No. of cows } & \multicolumn{2}{|c|}{ Milk samples 1 and 2} & \multicolumn{2}{|c|}{ Milk samples 2 and 3} \\
\hline & & $\mathrm{n}$ & Cluster change/consistent & $\mathrm{n}$ & Cluster change/consistent \\
\hline 2 & 43 & 41 & $4 / 37(3 \uparrow, 1 \downarrow)$ & 35 & $2 / 33(1 \uparrow, 1 \downarrow)$ \\
\hline $3+$ & 69 & 67 & $14 / 53(4 \uparrow, 10 \downarrow)$ & 63 & $8 / 55(4 \uparrow, 4 \downarrow)$ \\
\hline
\end{tabular}

Nielsen and Ingvartsen (2004) concluded that PRG might improve reproduction efficiency but recommended further studies to clarify this. Using various fertility measures, Hoedemaker et al. (2004) found no effect of PRG on reproduction in their study. In contrast, Borş et al. (2013) found significantly reduced CFI from PRG supplementation for all early-lactating cows. In our study, we found no overall significant effect of PRG on CFI. However, for parity $3+$ cows, we found a tendency $(P=0.07)$ for an interaction between PRG treatment and metabolic cluster, showing a beneficial effect of PRG treatment $(-15.5 \pm 8.4 \mathrm{~d})$ in imbalanced cows compared with healthy cows. This tendency may explain previous inconsistent results about the effect of PRG on reproduction, as the manifestation of this effect may depend of the metabolic status of the cows.

Our results of generally no beneficial effect (on milk production, biomarkers, or health problems) of PRG treatment in cows identified as being physiologically imbalanced, and only a few negative effects of the imbalanced metabolic cluster indicate that use of FT-MIR spectral data to classify cows in metabolic clusters was generally not a strong biomarker for truly metabolically imbalanced cows in the study population. Results of longer CFI, however, indicate that the FT-MIR clusters detected some elements of imbalanced status.

The incidence of metabolically imbalanced cows was 0.47 in herd A and 0.49 in herd B. This is considerably higher than in the study of Grelet et al. (2019). They found an incidence of imbalanced cows of 0.22 when predicted from milk samples as in our study, and an incidence of only 0.15 when imbalanced cows were determined by blood samples. The milk yield level in our study was higher (at a level of 12,000 kg of ECM/ cow) and hence might explain the high incidence of imbalanced cows. Grelet et al. (2019) tried to add cow milk yield into the prediction model but it only slightly improved prediction; therefore, it does not support that the high incidence of imbalanced cows was due to high milk yield in our study. A previous review also only found little evidence that high-yielding cows have an increased risk of production diseases (Ingvartsen et al., 2003). The high incidence of imbalanced cows in our study could be due instead to testing as early as 4 to 9
DIM, whereas in the study of Grelet et al. (2019) it was later, at 14 and 35 DIM.

A limitation of our study is that the number of truly metabolically imbalanced cows in the 2 study herds might have been low. We did not collect blood samples to serve as the gold standard. However, the number of dead cows of 5.4 and 5.0 per cow-year and the geometric mean SCC in delivered milk of 189,000 and 228,000 cells $/ \mathrm{mL}$ in the 2 study herds were close to 5.0 dead cows per cow-year and geometric mean SCC of 220,000 cells $/ \mathrm{mL}$, which were the mean values of all conventional Danish dairy herds in 2018, as reported in the report from SEGES/Danish Cattle (Frandsen, 2015). These measures indicate that general herd health was at a standard level; hence, we tested the new biomarker under herd conditions where the incidence of health problems was not at an atypical level. Another limitation is the assumption that PRG is an efficient treatment of metabolic imbalance. To our knowledge, no studies have proven a more efficient therapeutic and prophylactic treatment that herd personnel can handle at the cow level.

The procedure of sampling milk only one time per cow for detection of physiological imbalance is another limitation of our study. Therefore, we did repeat milk sampling on 1 and $2 \mathrm{~d}$ after first sampling at 4 to 9 DIM in herd B. The results from the repeated milk sampling indicated moderate to high robustness of using only one milk sample per cow. An inherent challenge of using milk samples and biomarkers of health problems in dairy cows is that the high-risk period is from a few days before calving to a few weeks after calving. However, due to colostrum production, we can only collect reliable milk samples after approximately $3 \mathrm{~d}$ after calving. Accordingly, the sampling procedure applied in this study had practical feasibility.

We optimized the experimental design to test group $\times$ treatment interaction; that is, to test whether detected imbalanced cows responded more to PRG than did healthy cows. Because the grouping was based on the original imbalanced cluster classification using FTMIR, the experimental design was weaker for testing the 4 milk metabolites (BHB, isoC, Mal, or Glut) as biomarkers. 
The predictive models documented by Grelet et al. (2019) showed higher predictive accuracy when using the separate models for primiparous and multiparous cows. This indicated that the predicted metabolic cluster may differ between parities. The effect of negative energy balance on blood levels of IGF-1, NEFA, and $\mathrm{BHB}$ is known to be different in the weeks after calving between primiparous and multiparous cows (Wathes et al., 2007). Because of biological differences between parity groups regarding the metabolic cluster definition and its effects in cows, we analyzed the effect of metabolic imbalance in separate models for parities 1,2 , and $3+$. If metabolic imbalance was consistent between parities, we could have analyzed all parities in one model, with greater power to detect significant differences.

\section{CONCLUSIONS}

We found that metabolic imbalance identified by means of milk FT-MIR spectra data during early lactation was, in general, not associated with subsequent impaired health and production, and that treatment with propylene glycol had no more effect on health and production in cows identified with imbalanced metabolic status. In conclusion, based on this experiment with 356 cows in 2 private dairy herds, we found a longer CFI in metabolically imbalanced cows but could not demonstrate overall benefits from the applied detection of cows in imbalanced metabolic status in early lactation and follow-up by treatment with PRG.

\section{ACKNOWLEDGMENTS}

We thank and acknowledge the owners and the staff of the two study farms, who assisted in the conduct of the study activities. We also thank Clément Grelet (Walloon Agricultural Research Center, Gembloux, Belgium) for cluster analyses, and Martin Bjerring (Aarhus University, Department of Animal Science, Tjele, Denmark) for data handling. This project received funding from the European Union's Seventh Framework Programme for research, technological development, and demonstration under grant agreement no. 613689. The views expressed in this publication are the sole responsibility of the authors and do not necessarily reflect the views of the European Commission. The authors have not stated any conflicts of interest.

\section{REFERENCES}

Bjerre-Harpøth, V., A. C. Storm, M. Vestergaard, M. Larsen, and T. Larsen. 2016. Effect of postpartum propylene glycol allocation to over-conditioned Holstein cows on concentrations of milk metabolites. J. Dairy Res. 83:156-164. https://doi.org/10.1017/ S0022029916000145.

Borş, S. L., G. Solcan, and A. Vlad-Sabie. 2014. Effects of propylene glycol supplementation on blood indicators of hepatic function, body condition score, milk fat-protein concentration and reproductive performance of dairy cows. Acta Vet. Brno 83:27-32. https:// doi.org/10.2754/avb201483010027.

Chagas, L. M., J. J. Bass, D. Blache, C. R. Burke, J. K. Kay, D. R. Lindsay, M. C. Lucy, G. B. Martin, S. Meier, F. M. Rhodes, J. R. Roche, W. W. Thatcher, and R. Webb. 2007. Invited review: New perspectives on the roles of nutrition and metabolic priorities in the subfertility of high producing dairy cows. J. Dairy Sci. 90:4022-4032. https://doi.org/10.3168/jds.2006-852.

Chaiyabutr, N., A. Faulkner, and M. Peaker. 1981. Changes in the concentrations of minor constituents of goat's milk during starvation and on refeeding of the lactating animal and their relationship to mammary gland metabolism. Br. J. Nutr. 45:149-157. https:// doi.org/10.1079/BJN19810087.

De Koster, J., M. Salavati, C. Grelet, M. A. Crowe, E. Matthews, R. O'Flaherty, G. Opsomer, L. FoldagerGplusE, and M. Hostens. 2019. Prediction of metabolic clusters in early-lactation dairy cows using models based on milk biomarkers. J. Dairy Sci. 102:26312644. https://doi.org/10.3168/jds.2018-15533.

Frandsen, J. 2015. Benchmarking in dairy production: "How to transform data to valuable decision support". Pages 63-67 in Proc. Krakow ICAR Technical Meeting 2015. ICAR Technical Series no. 19. ISBN: 92-95014-15-4. ICAR, Rome, Italy.

Grelet, C., A. Vanlierde, M. Hostens, L. Foldager, M. Salavati, K. Ingvartsen, M. Crowe, M. Sorensen, E. Froidmont, C. Ferris, C. Marchitelli, F. Becker, T. Larsen, F. Carter, and F. Dehareng. 2019. Potential of milk mid-IR spectra to predict metabolic status of cows through blood components and an innovative clustering approach. Animal 13:649-658. https://doi.org/10.1017/ S1751731118001751.

Hoedemaker, M., D. Prange, H. Zerbe, J. Frank, A. Daxenberger, and H. H. D. Meyer. 2004. Peripartal propylene glycol supplementation and metabolism, animal health, fertility, and production in dairy cows. J. Dairy Sci. 87:2136-2145. https://doi.org/10.3168/ jds.S0022-0302(04)70033-8.

Ingvartsen, K. L. 2006. Feeding- and management-related diseases in the transition cow: Physiological adaptations around calving and strategies to reduce feeding-related diseases. Anim. Feed Sci. Technol. 126:175-213. https://doi.org/10.1016/j.anifeedsci.2005 .08 .003 .

Ingvartsen, K. L., R. J. Dewhurst, and N. C. Friggens. 2003. On the relationship between lactational performance and health: Is it yield or metabolic imbalance that cause production diseases in dairy cattle? A position paper. Livest. Prod. Sci. 83:277-308. https:// doi.org/10.1016/S0301-6226(03)00110-6.

Ingvartsen, K. L., and K. Moyes. 2013. Nutrition, immune function and health of dairy cattle. Animal 7(s1):112-122. https://doi.org/ 10.1017/S175173111200170X.

Larsen, T. 2014. Fluorometric determination of free and total isocitrate in bovine milk. J. Dairy Sci. 97:7498-7504. https://doi.org/ 10.3168/jds.2014-8018.

Larsen, T., L. Alstrup, and M. R. Weisbjerg. 2016. Minor milk constituents are affected by protein concentration and forage digestibility in the feed ration. J. Dairy Res. 83:12-19. https://doi.org/ $10.1017 /$ S0022029915000692.

Larsen, T., and C. Fernández. 2017. Enzymatic-fluorometric analyses for glutamine, glutamate and free amino groups in protein-free plasma and milk. J. Dairy Res. 84:32-35. https://doi.org/10.1017/ S0022029916000789.

Larsen, T., and N. I. Nielsen. 2005. Fluorometric determination of $\beta$-hydroxybutyrate in milk and blood plasma. J. Dairy Sci. 88:2004-2009. https://doi.org/10.3168/jds.S0022-0302(05)72876 $-9$.

LeBlanc, S. 2010. Monitoring metabolic health of dairy cattle in the transition period. J. Reprod. Dev. 56(S):S29-35. https://doi.org/ $10.1262 /$ jrd.1056S29. 
Liu, Q., C. Wang, W. Z. Yang, W. W. Zhang, X. M. Yang, D. C. He, K. H. Dong, and Y. X. Huang. 2009. Effects of feeding propylene glycol on dry matter intake, lactation performance, energy balance and blood metabolites in early lactation dairy cows. Animal 3:1420-1427. https://doi.org/10.1017/S175173110999036X.

Lomander, H., J. Frössling, K. L. Ingvartsen, H. Gustafsson, and C. Svensson. 2012. Supplemental feeding with glycerol or propylene glycol of dairy cows in early lactation-Effects on metabolic status, body condition, and milk yield. J. Dairy Sci. 95:2397-2408. https://doi.org/10.3168/jds.2011-4535.

McArt, J. A. A., D. V. Nydam, and G. R. Oetzel. 2012. A field trial on the effect of propylene glycol on displaced abomasum, removal from herd, and reproduction in fresh cows diagnosed with subclinical ketosis. J. Dairy Sci. 95:2505-2512. https://doi.org/10.3168/ jds.2011-4908.

McArt, J. A. A., D. V. Nydam, P. A. Ospina, and G. R. Oetzel. 2011. A field trial on the effect of propylene glycol on milk yield and resolution of ketosis in fresh cows diagnosed with subclinical ketosis. J. Dairy Sci. 94:6011-6020. https://doi.org/10.3168/jds.2011 $-4463$.

Moyes, K. M., T. Larsen, and K. L. Ingvartsen. 2013. Generation of an index for physiological imbalance and its use as a predictor of primary disease in dairy cows during early lactation. J. Dairy Sci. 96:2161-2170. https://doi.org/10.3168/jds.2012-5646.

Nielsen, N. I., and K. L. Ingvartsen. 2004. Propylene glycol for dairy cows. A review of the metabolism of propylene glycol and its effects on physiological parameters, feed intake, milk production and risk of ketosis. Anim. Feed Sci. Technol. 115:191-213. https://doi .org/10.1016/j.anifeedsci.2004.03.008.
Overton, T. R., J. A. A. McArt, and D. V. Nydam. 2017. A 100year review: Metabolic health indicators and management of dairy cattle. J. Dairy Sci. 100:10398-10417. https://doi.org/10.3168/jds .2017-13054.

Pires, J., T. Larsen, and C. Leroux. 2018. Milk metabolites as noninvasive indicators of physiological state and energy balance of early lactation cows. Abstract 420 in Proc. 10th Int. Symp. Nutr. Herbivores (ISNH). ISNH, Clermont-Ferrand, France.

R Core Team. 2018. R: A Language and Environment for Statistical Computing. R Foundation for Statistical Computing, Vienna, Austria. http:// www.Rproject.org/.

Shankare Gowda, A. J., M. Devaraj, and A. Krishnaswamy. 2015. The influence of feeding propylene glycol, rumen-protected fat and protein on milk yield in early lactating cows. Int. J. Sci. Res. (Ahmedabad) 4:1254-1257.

Wathes, D. C., Z. Cheng, N. Bourne, V. J. Taylor, M. P. Coffey, and S. Brotherstone. 2007. Differences between primiparous and multiparous dairy cows in the inter-relationships between metabolic traits, milk yield and body condition score in the periparturient period. Domest. Anim. Endocrinol. 33:203-225. https://doi.org/10.1016/j .domaniend.2006.05.004.

\section{ORCIDS}

S. Østergaard (® https://orcid.org/0000-0002-8514-5414

M. A. Krogh ๑ https://orcid.org/0000-0003-0731-6676

V. H. S. Oliveira @ https://orcid.org/0000-0003-3817-9192

N. D. Otten (® https://orcid.org/0000-0003-1004-1474 